\section{Commentary: Peeking into the personalized poking future}

\author{
Matthew J. Ashbrook, MD, MPH, ${ }^{\mathrm{a}}$ and \\ Anthony W. Kim, MD ${ }^{\mathrm{a}, \mathrm{b}}$
}

Metastases to the lung can occur from a variety of primary extrapulmonary malignancies, often requiring multidisciplinary care. Although surgical metastasectomy often is offered for its theoretical curative potential, employing a local therapy to treat what really is a biologically systemic problem represents a thought process that is part science, part philosophy, and part optimism. This thought process is never more challenged when faced with multiple metastases to the lung. In this context, resecting small and deep metastases can be disconcerting for many thoracic surgeons, as the resection of these lesions requires a considerably greater amount of lung tissue to be removed relative to a peripheral lesion of the same size. Consequently, alternative approaches for addressing malignancies that have metastasized to the lung, especially of the smaller and deeper sort, have always garnered interest.

Harrison and colleagues ${ }^{1}$ should be congratulated for their series on image-guided combined ablation and resection in thoracic surgery, coined iCART, as it establishes a model in which the thoracic surgeon is more effective in managing metastatic disease in a single anesthetic setting. Their hybrid treatment paradigm, the coupling of a nonsurgical and surgical approach to address metastases, performed in a hybrid operating suite, the modern-day version of a hybrid treatment platform, provides a look

\footnotetext{
From the a Department of Surgery and ${ }^{\mathrm{b}}$ Division of Thoracic Surgery, Keck School of Medicine, University of Southern California, Los Angeles, Calif.

Disclosures: The authors reported no conflicts of interest. Dr Ashbrook is a Lieutenant in the United States Navy, Medical Corps, Naval Medical Leader, and Professional Development Command. The views expressed in this manuscript reflect the results of research conducted by the author(s) and do not necessarily reflect the official policy or position of the Department of the Navy, Department of Defense, nor the US Government.

The Journal policy requires editors and reviewers to disclose conflicts of interest and to decline handling or reviewing manuscripts for which they may have a conflict of interest. The editors and reviewers of this article have no conflicts of interest.

Received for publication May 12, 2021; revisions received May 12, 2021; accepted for publication May 14, 2021; available ahead of print May 21, 2021.

Address for reprints: Anthony W. Kim, MD, Division of Thoracic Surgery, Keck School of Medicine, University of Southern California, 1510 San Pablo St, Suite 514, Los Angeles, CA 90033 (E-mail: anthony.kim@med.usc.edu). JTCVS Techniques 2021;9:163-4

2666-2507

Copyright (C) 2021 The Authors. Published by Elsevier Inc. on behalf of The American Association for Thoracic Surgery. This is an open access article under the CC BY-NCND license (http://creativecommons.org/licenses/by-nc-nd/4.0/).

https://doi.org/10.1016/j.xjtc.2021.05.015
}

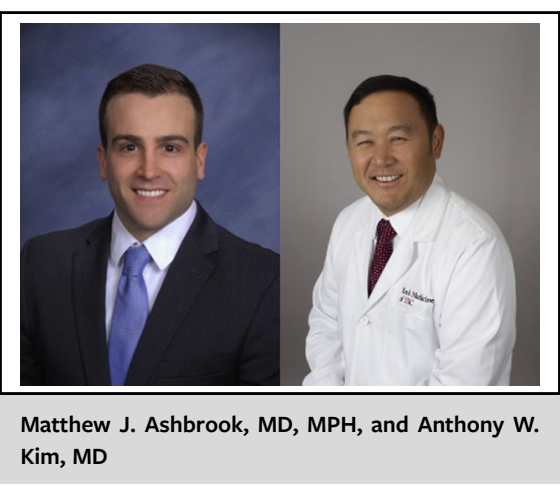

$$
\begin{aligned}
& \text { CENTRAL MESSAGE } \\
& \text { Image-guided combined ablation } \\
& \text { and resection in thoracic surgery, } \\
& \text { or iCART, represents a compre- } \\
& \text { hensive and personalized hybrid } \\
& \text { nonsurgical and surgical } \\
& \text { approach to treating multiple } \\
& \text { lung metastases. }
\end{aligned}
$$

into what the future of treating multiple foci of metastases may bring.

In their retrospective case series of 5 procedures in 4 patients, the authors make the compelling argument for using iCART. In their hybrid operating suite while patients were under general anesthesia, the authors employed computed tomography scanning to localize multiple metastatic lesions for ablation with percutaneous microwave ablation as well as to wire localize lesions for subsequent thoracoscopic wedge resections. At a maximum follow-up period of 24 months (median: 11 months), there was no recurrence. From their experience, the authors conclude that iCART is a form of therapy for patients with multiple pulmonary metastasis that avoids multiple sessions of anesthesia, decreased total procedure time and transport, and increased patient safety and comfort. Although these iCART attributes may not entirely address the complex biology of metastases, the sense that all the visible and palpable disease in the chest is being treated comprehensively in a singular setting is a gesture toward each patient that is truly personalized.

In due time and with larger studies, outcomes associated with percutaneous microwave ablation or other ablative therapies, such as radiofrequency, cryotherapy, and newer technologies, will yield comparative data that will amass greater interest. From a broader perspective, continued refinement may result in the percutaneous approach being 
abandoned altogether as advances in endobronchial approaches, possibly augmented by machine learning and artificial intelligence, may be coupled with ablative therapies to treat multiple metastatic lesions. This future hybrid of another therapeutic paradigm to an evolving technical platform may even spell the exclusion of an actual surgical component. While a potential threat to the livelihood of many thoracic surgeons, the history of thoracic surgery is one in which adapting to shifting therapeutic paradigms has rewarded those like Harrison and colleagues for being forward-thinking and embracing change to their advantage. In that way, thoracic surgeons should thank these authors for providing us a glimpse of that which is ahead-a peek into a future that has a lot of needle pokes rather than scalpel incisions.

\section{Reference}

1. Harrison OJ, Sarvananthan S, Tamburrini A, Peebles C, Alzetani A. Image-guided combined ablation and resection in thoracic surgery for the treatment of multiple pulmonary metastases: a preliminary case series. J Thorac Cardiovasc Surg Tech. 2021;9:156-62. 